\title{
NANOFIBER PRODUCTION FROM LIQUEFIED HAZELNUT SHELL WITH THE ADDITION OF REDUCED GRAPHENE OXIDE AND POLYVINYL PYRROLIDONE
}

\author{
ÖMER ÖNAL, ${ }^{*}$ MUSTAFA YAZICI, ${ }^{* *}$ ISMAIL TIYEK, ${ }^{* * *}$ OĞUZHAN KONUŞ, \\ MEHMET HAKKI ALMA**** and TUFAN SALAN* \\ *Department of Material Science and Engineering, Graduate School of Natural and Applied Sciences, \\ Kahramanmaraş Sütçü Imam University, 46050, Onikişubat, Kahramanmaraş, Turkey \\ ${ }^{* *}$ Department of Mathematics and Science Education, Faculty of Education, \\ Kahramanmaraş Sütçü İmam University, 46050, Onikişubat, Kahramanmaraş, Turkey \\ ${ }^{* * *}$ Department of Textile Engineering, Faculty of Engineering and Architecture, \\ Kahramanmaraş Sütçü İmam University, 46050, Onikişubat, Kahramanmaraş, Turkey \\ ***** Department of Industrial Engineering of Forestry, Faculty of Forestry, \\ Kahramanmaraş Sütçü İmam University, 46050, Onikişubat, Kahramanmaraş, Turkey \\ \Corresponding author: Ismail Tiyek, ismailtiyek@gmail.com
}

Received April 7, 2020

In this study, in order to produce nanofibers from waste hazelnut shells, a lignocellulosic biomass, firstly, liquefied hazelnut shell (LHS) was obtained by liquefaction of waste hazelnut shells using phenol and some chemicals. Then, reduced graphene oxide (RGO) was produced by Hummers' method. RGO and polyvinyl pyrrolidone (PVP) were added to LHS, in certain proportions, to form seven different LHS-RGO-PVP solutions with ethanol/dimethylformamide (EtOH/DMF). From these solutions, nanofiber surfaces were obtained by a semi-industrial electrospinning device. The morphology of the nanofibers and the properties of the electrospinning solution were investigated, and it was observed that the optimum nanofibers were obtained from $7.5 \%$ LHS/10\% PVP/5.6\% RGO solution by the electrospinning method. It has been determined that the conductivity is slightly reduced by the addition of RGO to the solution, the viscosity is greatly reduced, the nanofiber diameters are reduced by approximately half, and thinner nanofibers are obtained.

Keywords: liquefied hazelnut shell, reduced graphene oxide, polyvinyl pyrrolidone, multi-needle electrospinning, nanofiber

\section{INTRODUCTION}

Wood is one of the most important renewable energy sources. ${ }^{1-3}$ Liquefaction of wood is carried out using an acid or alkaline catalyst, with phenol or polyhydric alcohols. ${ }^{4-7}$ In the literature, there are many studies on the phenolation of wood wastes using different acids, such as hydrochloric, ${ }^{8}$ sulfuric, ${ }^{9}$ oxalic, ${ }^{10}$ phosphoric ${ }^{11}$ etc., alkalis, ${ }^{6}$ such as sodium hydroxide $(\mathrm{NaOH})$, and metallic salts, ${ }^{6}$ such as magnesium sulfate $\left(\mathrm{MgSO}_{4}\right)$, as chemical catalysts. According to the data provided by the Turkish Statistical Institute (TUIK), and presented in Table 1, Turkey has rich resources in terms of hazelnut production, with an average share of $65.53 \%$ of the world's hazelnut production in the years $2010 / 11$ and $2017 / 18 .^{12}$
Hazelnut shells resulting as residue are either used as fuel or disposed of as waste. Considering this, this study aimed to find a new application for this residue, so as to valorize it and turn it into a value-added product.

Nowadays, many consumable commercial products are manufactured from synthetic polymers. These resources, which cannot be renewed and biodegradable, have disadvantages in terms of their insufficient availability and serious environmental pollution. ${ }^{13,14}$ Innovative technologies with bio-based products can reduce the dependence on fossil resources. Cellulose and lignin are the most and the second most abundant components of plant biomass, respectively. Agro- 
industrial biomass, comprising lignocellulosic waste, is inexpensive, renewable and abundant, providing a unique natural resource for large-scale manufacture of cost-effective products. ${ }^{15,16-18}$ As a by-product of the cellulose and paper industry, lignin is often burned for energy recovery. Lignin can be used for sustainable production processes based on renewable resources not only for energy purposes, but also as a resource for chemicals and plastics. $^{15,18}$

Table 1

World hazelnut production ${ }^{12}$

\begin{tabular}{lcccccccc}
\hline \multirow{2}{*}{ Countries } & \multicolumn{7}{c}{ Hazelnut production by years (tons) } \\
\cline { 2 - 9 } & $2010 / 11$ & $2011 / 12$ & $2012 / 13$ & $2013 / 14$ & $2014 / 15$ & $2015 / 16$ & $2016 / 17$ & $2017 / 18$ \\
\hline Turkey & 600,000 & 430,000 & 660,000 & 549,000 & 412,000 & 646,000 & 420,000 & 675,000 \\
Italy & 107,000 & 140,000 & 84,000 & 132,000 & 100,000 & 125,000 & 130,000 & 100,000 \\
USA & 24,500 & 35,000 & 32,000 & 35,000 & 36,300 & 43,500 & 32,000 & 34,000 \\
Azerbaijan & 39,000 & 55,000 & 40,000 & 30,000 & 25,000 & 50,000 & 35,000 & 45,000 \\
Georgia & 40,000 & 30,000 & 28,000 & 35,000 & 35,000 & 40,000 & 40,000 & 60,000 \\
Spain & 20,000 & 22,000 & 16,000 & 19,500 & 19,500 & 20,000 & 21,000 & 19,000 \\
Other & 27,000 & 27,000 & 25,000 & 25,000 & 25,000 & 45,000 & 42,000 & 44,500 \\
Total & 857,500 & 739,000 & 885,000 & 825,500 & 660,773 & 969,500 & 720,000 & 997,500 \\
Turkey's share (\%) & 69.97 & 58.19 & 74.58 & 66.51 & 62.35 & 66.63 & 58.33 & 67.67 \\
\hline
\end{tabular}

The use of biomass resources will be a major solution to the above-mentioned problems and many techniques are currently being developed to effectively use biomass resources. ${ }^{19,20}$ Lignocellulosic biomasses mainly consist of three polymers: cellulose, hemicelluloses and lignin, representing the three main constituents of the cell walls of plants, in which they are not uniformly dispersed. $^{21}$ Hazelnut shell is a lignocellulosic biomass material containing $26.7 \%$ cellulose, $30.29 \%$ hemicellulose and $43.01 \%$ lignin. $^{22-23}$ Lignocellulosic biomass materials are used as a source for renewable energy and materials. While waste hazelnut shell is generally either burned or discarded, it has been reported that it can be liquefied in the laboratory by the liquefaction technique in order to use it effectively to produce high value-added products. ${ }^{24}$

Polyvinyl pyrrolidone (PVP) is a polymer that can be used in the electrospinning method due to its good adhesion, complexation properties and solubility in water and various organic solvents. PVP is typically used to produce fibers from materials that cannot be spun by electrospinning, acting as a carrier polymer or partner. ${ }^{25}$ Yang et $a l$. found in their study that a mixture of ethanol and DMF, with a mass ratio of $50 / 50$, is the best solvent system to obtain an ultra-thin PVP nanofiber. ${ }^{26}$ As it is known that, theoretically, it is difficult to convert the graphene doped liquefied hazelnut shell to nanofibers by electrospinning, the PVP polymer was used in this study to produce nanofibers by electrospinning from graphene doped liquefied hazelnut shell.
Graphene is a material with two dimensions, which is unique with its superior electrochemistry, electrical conductivity, optical, thermal and mechanical properties. ${ }^{27-30}$ Graphene, due to its superior properties, is increasingly used in nanosurface production at an industrial level. Graphene has applications in polymer supports, gas sensors, composite materials, biological sensors, hydrogen storage devices, field effect transistors, transparent touch screens, lithium ion batteries and light panels. ${ }^{31-33}$ Graphene can be produced by different methods. However, the chemical reduction method is the most common. In this method, graphite is first converted to graphene oxide (GO) by chemical oxidation using a strong acid and oxidant, forming numerous functional groups, such as hydroxyl $(-\mathrm{OH})$, epoxy (-COC), carbonyl (-CO) and carboxyl (-COOH). GO has a hydrophilic character due to these functional groups. This structure decreases the conductivity of $\mathrm{GO}$, causing restrictions on the use of GO in electronic applications. Therefore, the functional groups of GO should be removed by reduction to obtain reduced graphene oxide (RGO). Hydrazine hydrate and sodium borohydride are the main chemicals used for the reduction process. ${ }^{34-38}$

Electrospinning is the ideal method for nanofiber production. The nanofibers exhibit superior properties, such as large surface area by volume, very small pore sizes, flexible surface functionality, and mechanical properties. ${ }^{27,39}$ Owing to the increased use of the electrospinning method, researchers have come up with different 
production methods. In the electrospinning method using a solution, the polymer can be dissolved in an ideal solvent under suitable conditions and used in the electrospinning process. ${ }^{27}$ The synthesis of new polymers that can be spun by the electrospinning method has emerged as a subject of research.

In recent years, with the depletion of oil reserves and environmental problems, there has been a rising interest in utilizing sustainable feedstock, such as biomass, to obtain various renewable products as an alternative to petroleumbased materials. Especially, phenolated biomass, obtained by using the liquefaction technique, was recently used for the production of nanofibers via the electrospinning method. ${ }^{25,40}$ However, liquefied biomass is a kind of viscous liquid rich in phenolics and cellulosic oligosaccharides. The main composition of liquefied biomass consists of relatively low average molecular weight compounds, ranging from a few hundred to several thousand. Theoretically, it is hard to obtain electrospun fibers from liquefied biomass. Because the average molecular weight of polymer solutions used in the electrospinning process is generally more than several hundred thousand. However, mixing an un-spinnable material with a spinnable polymer is a commonly used approach for the electrospinning technique. ${ }^{25}$

Also, it has been reported that graphenereinforced nanocomposites have good performance, especially in terms of mechanical properties, as compared with other nanofillers, such as carbon nanotubes. This nanomaterial was added to polymer matrixes in order to enhance the mechanical and electrical properties along with morphological properties, such as diameter and porosity of the composite materials. Additionally, the high electrical field obtained during the electrospinning process can enhance the interactions between the nanofiller and the polymer matrix, developing a filler/matrix interface at a molecular scale. ${ }^{37,41}$

Thus, the aim of this research was to produce PVP and PVP/RGO doped LHS nanofibers, using liquefied waste hazelnut shells and to characterize their properties. In the experiments, lignocellulose based biomass waste hazelnut shells were effectively liquefied in the laboratory and doped with graphene in order to produce high valueadded products. GO was synthesized from graphite by the modified Hummers' method $^{29,32,34,42-43}$ and then RGO was produced from GO by the chemical reduction method. ${ }^{32,34}$
Theoretically, since it is difficult to convert the graphene doped liquefied hazelnut shell to nanofibers by electrospinning, PVP, a well-known polymer that can be used for electrospinning, was added to the LHS-RGO mixture, in certain proportions, due to its above-mentioned excellent properties. Then, the mixtures were dissolved in EtOH-DMF solvent mixtures and LHS-RGOPVP/EtOH-DMF solutions at different concentrations, and nanofibers were produced from PVP and PVP/RGO doped LHS spinning solutions by the electrospinning method. Nanofibers were obtained by electrospinning with appropriate spinning parameters. Finally, some analyses were carried out to characterize the obtained nanofibers. The obtained nanofibers had decent properties and would be of interest for several applications, such as in sensor technology, membrane technology, battery technology as anode material, and in supercapacitor technology as electrode material after carbonization.

\section{EXPERIMENTAL}

\section{Materials}

In this study, graphite powder $(<20 \mu \mathrm{m})$, potassium permanganate $\left(\mathrm{KMnO}_{4}\right)$ and sodium nitrate $\left(\mathrm{NaNO}_{3}\right.$, $99.5 \%$ ), which were used to synthesize GO by the modified Hummers' method, and phenol, sulfuric acid $\left(\mathrm{H}_{2} \mathrm{SO}_{4}, 95-97 \%\right)$, methanol and sodium hydroxide $(\mathrm{NaOH})$, which were required to liquefy the hazelnut shell, were supplied by Merck, Germany. Hydrogen peroxide $\left(\mathrm{H}_{2} \mathrm{O}_{2}, 35.7 \%\right)$, hydrazine hydrate $\left(\mathrm{H}_{6} \mathrm{~N}_{2} \mathrm{O}\right.$, $80 \%)$, ethanol $(\mathrm{EtOH})$ and sulfuric acid $\left(\mathrm{H}_{2} \mathrm{SO}_{4}, 95 \%\right)$ were supplied by Sigma Aldrich, Germany. Waste hazelnut shells were collected from the Black Sea region in Turkey. The hazelnut shells were ground using a high-speed blade grinder to obtain fine particles, and then these particles were sieved by using a vibrating screen. Particles of 60-80 mesh sizes were used for the experiments.

\section{Methods \\ Liquefaction of waste hazelnut shells}

In order to liquefy the hazelnut shell, first it was dried in the oven for 12 hours at $103{ }^{\circ} \mathrm{C}$. The moisture content of the dried hazelnut shell was measured as $3 \%$. $90 \mathrm{~g}$ of phenol was weighed, so that the phenolhazelnut shell ratio was $3 / 1$ (30 g of oven-dried hazelnut shell). $2.7 \mathrm{~g}$ of sulfuric acid, corresponding to $3 \%$ of the amount of phenol, was weighed. In the experiments, $30.9 \mathrm{~g}$ of hazelnut shell was used considering $3 \%$ moisture content of $30 \mathrm{~g}$ raw hazelnut shell. The mixture of hazelnut shells, phenol and sulfuric acid in a $500 \mathrm{~mL}$ glass flask was reacted in a microwave oven under $350 \mathrm{~W}$ power at $192{ }^{\circ} \mathrm{C}$, with continuous stirring at $200 \mathrm{rpm}$ for $90 \mathrm{~min}$. At the end of this process, the obtained product was diluted with 
methanol and filtered under vacuum using filter paper to remove unreacted substances. The $\mathrm{pH}$ of the filtrate was measured and found to be 2.66. To neutralize the liquefied fraction, $0.98 \mathrm{~g}$ of $\mathrm{NaOH}$ was added to the mixture until $\mathrm{pH} 7$ was reached. Subsequently, filtration was carried out again in order to separate the salts formed by the reaction of alkali (sodium hydroxide) and acid (sulfuric acid), and the remaining salts were removed. Finally, methanol was removed on a rotary evaporator at $50{ }^{\circ} \mathrm{C}$ and $90 \mathrm{rpm}$ for 4 hours and liquefied hazelnut shell (LHS) was obtained.

\section{Synthesis of graphene oxide (GO)}

The graphene oxide used in the study was obtained by the modified Hummers' method. ${ }^{29,32,34,42-43}$ For this purpose, $5 \mathrm{~g}$ of graphite and $2.5 \mathrm{~g}$ of sodium nitrate $\left(\mathrm{NaNO}_{3}\right)$ were added to a beaker placed in an ice-bath (temperature $\approx 0{ }^{\circ} \mathrm{C}$ ). Thereafter, $115 \mathrm{~mL}$ of sulfuric acid $\left(\mathrm{H}_{2} \mathrm{SO}_{4}\right)$ was added slowly to the beaker. It was stirred for 1 hour at a very low speed $(5 \mathrm{rpm})$ with the aid of a magnetic stirrer. $15 \mathrm{~g}$ of potassium permanganate $\left(\mathrm{KMnO}_{4}\right)$ was added slowly to the beaker in an ice bath. The speed of the magnetic stirrer was set to $25 \mathrm{rpm}$ and it was stirred for 2 hours at a temperature not exceeding $40{ }^{\circ} \mathrm{C}$. The mixture in the beaker was transferred to a double flask. $500 \mathrm{~mL}$ of deionized water was then added to the mixture. After the addition of water, the color of the mixture changed from black to light brown. The flask was then remounted to the condenser and stirred at $25 \mathrm{rpm}$ for 1 hour. $8.403 \mathrm{~mL}$ of hydrogen peroxide $\left(\mathrm{H}_{2} \mathrm{O}_{2} 35.7 \%\right)$ was added to the mixture and processed for 2 hours on a magnetic stirrer at a constant temperature of $40{ }^{\circ} \mathrm{C}$. The color of the mixture turned brown. An Erlenmeyer flask and a gas scrubber were connected to the vacuum device and a Buchner funnel was placed on the flask so that no air could leak. The mixture was washed 14 times with deionized water and filtered. Filtration was performed slowly, and the $\mathrm{pH}$ was increased to 7. After the filtration process, the remaining material was transferred to the watch glass and oven-dried at $50{ }^{\circ} \mathrm{C}$ for 24 hours, and 9.69 grams of graphene oxide (GO) was obtained.

\section{Production of reduced graphene oxide (RGO)}

To obtain graphene from graphene oxide (GO), $3 \mathrm{~g}$ of GO was first added to $900 \mathrm{~mL}$ of deionized water and the mixture was processed for 24 hours in a magnetic stirrer at $35{ }^{\circ} \mathrm{C}$ and $300 \mathrm{rpm}$, and then dispersed in an ultrasonic bath at $12{ }^{\circ} \mathrm{C}$ for 2 hours. 90 $\mathrm{mL}$ of hydrazine hydrate was then added slowly to the solution. The mixture was connected to the condenser. It was stirred at $90{ }^{\circ} \mathrm{C}$ for 24 hours in a magnetic stirrer. Filtration was then carried out several times with ethanol. It was filtered with deionized water until $\mathrm{pH}$ 7. The resulting material was kept in the dryingoven at $50{ }^{\circ} \mathrm{C}$ for 24 hours and 1.28 grams of RGO was obtained.
Nanofiber spinning process from PVP and PVP/RGO doped LHS solutions

In preliminary studies, nanofiber extraction by the electrospinning method could not be performed from only LHS containing drafting solutions. Therefore, in order to produce nanofibers from LHS, PVP polymer, a material suitable for electrospinning, was added to the solution. In addition, in order to improve the properties of the produced nanofiber surfaces, RGO doping was performed. Seven different electrospinning draft solutions were prepared in EtOH-DMF binary solvent mixture, $50 \%-50 \%$ by weight, in the following ratios: 6\% LHS/8\% PVP, 7.5\% LHS/8\% PVP, $7.5 \%$ LHS/10\% PVP, $7.5 \%$ LHS/10\% PVP/5.6\% RGO, 6\% LHS/10\% PVP/5.6\% RGO, 7.5\% LHS/8\% PVP/5.6\% RGO, $7.5 \%$ LHS/10\% PVP/4\% RGO, for spinning nanofiber using the electrospinning apparatus. These mixtures were treated in an ultrasonic bath, with a magnetic stirrer, then injected into the syringe and placed in the apparatus for electrospinning. As a result of the preliminary tests, the optimum device operating conditions were adjusted to $21.5 \mathrm{kV}$, solution feed rate of $6 \mathrm{~mL} / \mathrm{h}$ and distance between nozzle and sample of $18.1 \mathrm{~cm}$. According to these parameters, nanofibers were obtained by spinning fiber in the electrospinning device. The same instrument parameters were used for all the samples.

\section{Characterization of spinning solutions and nanofibers}

The morphology of the obtained nanofibers was characterized by scanning electron microscopy (SEM Model EVO LH10, ZEISS, Germany) and Fourier transform infrared spectroscopy (FTIR Model Spectrum 400 FTIR, Perkin Elmer, USA) analyses were performed to determine the chemical structure of nanofibers. Zeta potential measurements of the solution and obtained nanofiber surfaces were performed with a Zetasizer Nano ZS90 (Malvern Instruments, UK). Water was used as a solvent. Electrical conductivity (Hanna Edge EC Meter, USA) and viscosity (Polyscience Standart Model 9106, USA) values of the electrospinning solutions and electrical conductivity (Lucas Labs Pro4, USA) values of graphene and nanofibers were also measured. Finally, the effects of the properties and contents of the electrospinning solutions on the morphology and properties of the nanofibers were examined, using the results obtained from these analyses.

\section{RESULTS AND DISCUSSION}

It is known that the electrical conductivity and viscosity properties of the electrospinning solution used in the production of nanofibers play an important role in the electrospinning process. The conductivity and viscosity values of the electrospinning solution and the nanofiber 
diameters measured by the electron microscope (SEM) are given in Table 2.

Similarly to viscosity and surface tension, conductivity is an important parameter in the application of electrospinning. Since LHS contains many phenolic groups and small molecule carbohydrates, nanofibers cannot be formed by electrospinning without macromolecular additives. In order to increase the spinnability of LHS, the PVP polymer, which acts as a carrier polymer or partner, is added to the electrospinning solution. Each chemical used in the solution can change the conductivity of the solution. When comparing LP1 with LP2 samples and LPR1 with LPR2 samples, it was seen that the increase of the LHS amount increased the conductivity of the electrospinning solutions. When comparing LP3 with LPR1 samples and LPR1 with LPR4 samples, it was observed that the solution conductivity decreased by adding or increasing the amount of RGO to the solution. With the decrease in conductivity, a significant decrease in nanofiber diameter was observed and thinner nanofibers were obtained. The results showed that conductivity in the range from 38.4 $\mu \mathrm{S} / \mathrm{cm}$ to $16.41 \mu \mathrm{S} / \mathrm{cm}$ was suitable for the electrospinning solution for the preparation of nanofibers. The ideal nanofiber diameter is produced by the addition of RGO.

Angammana and Jayaram ${ }^{44}$ investigated the effects of changing the conductivity of polyethylene oxide (PEO)/water solution on the electrospinning process and fiber morphology. Their results demonstrated that the average jet current firstly increased with the increasing conductivity of the solution and later diminished slowly. Besides, the average fiber diameter diminished with an increase in the conductivity of the solution. They reported that these results could be entirely related to the distribution of the surface charge around the electrospun jet and the variation in the tangential electric field along the

Table 2

Conductivity and viscosity values of electrospinning solutions and nanofiber diameters

\begin{tabular}{clcccc}
\hline Sample & Solution content & Conductivity & Viscosity & \multicolumn{2}{c}{ Nanofiber diameters } \\
\cline { 4 - 5 } & & $(\mu \mathrm{S} / \mathrm{cm})$ & $\left(\mathrm{kg} / \mathrm{m}^{3}\right)$ & Mean $(\mathrm{nm})$ & Std. deviation \\
\hline LP1 & 6\% LHS/8\% PVP & 24.81 & 930 & 415.54 & 97.59 \\
LP2 & $7.5 \%$ LHS/8\% PVP & 38.4 & 938 & 403.19 & 91.58 \\
LP3 & $7.5 \%$ LHS/10\% PVP & 30.0 & 963 & 537.65 & 131.12 \\
LPR1 & $7.5 \%$ LHS/10\% PVP/5.6\% RGO & 21.06 & 943 & 339.24 & 98.05 \\
LPR2 & $6 \%$ LHS/10\% PVP/5.6\% RGO & 16.41 & 916 & 277.41 & 76.82 \\
LPR3 & $7.5 \%$ LHS/8\% PVP/5.6\% RGO & 20.65 & 932 & 262.32 & 65.14 \\
LPR4 & $7.5 \%$ LHS/10\%PVP/4\% RGO & 36.3 & 925 & 257.57 & 50.22 \\
\hline
\end{tabular}

surface of the fluid. Low conductivity of a polymer solution hinders a proper electrospinning process because of the absence of surface charge of a fluid droplet to form a Taylor cone. Similarly, very high conductive solutions will not be able to form a Taylor cone because of the extinct tangential electric field along the surface of the fluid droplet.

When the viscosity results of the produced nanofiber solutions are examined, it may be seen that PVP and LHS increase the solution viscosity and RGO addition decreases the solution viscosity. This is thought to be due to the fact that PVP and LHS have a high specific gravity, while RGO has low specific gravity. Viscosity is one of the factors affecting the physical properties of nanofibers, such as diameter and length during electrospinning. With the addition of RGO, the viscosity decreased greatly. In addition, nanofiber diameters have been reduced by about half and thinner nanofibers have been obtained. The amount of RGO added to the solution appeared to affect the viscosity. According to these results, it is noted that the decrease in viscosity has a direct effect on nanofiber diameters. Therefore, an extremely viscous solution is not preferred in electrospinning studies. In addition, SEM images show that the fibers are ideal in diameter and length, indicating that the solutions prepared for electrospinning have an ideal viscosity. The conductivity and viscosity of the electrospinning solution were found to have the desired effect on nanofiber diameter. The results show that it is possible to obtain electrospun nanofibers by introducing a certain amount of PVP polymer and

Scanning electron microscopy (SEM) images of nanofibers produced by the electrospinning method from LHS/PVP/RGO solutions prepared in different ratios are given in Figure 1. RGO into the liquefied hazelnut shell. 


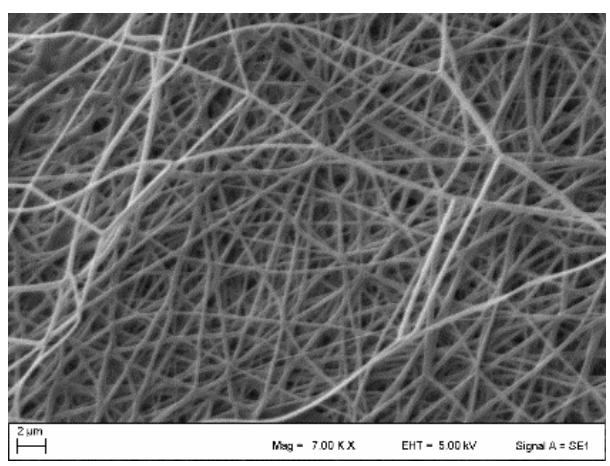

a)

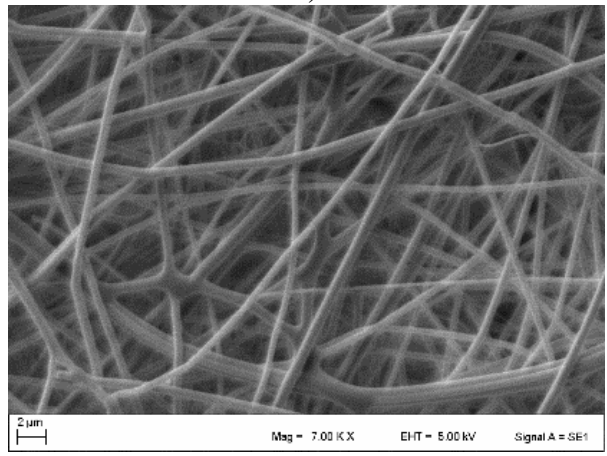

c)

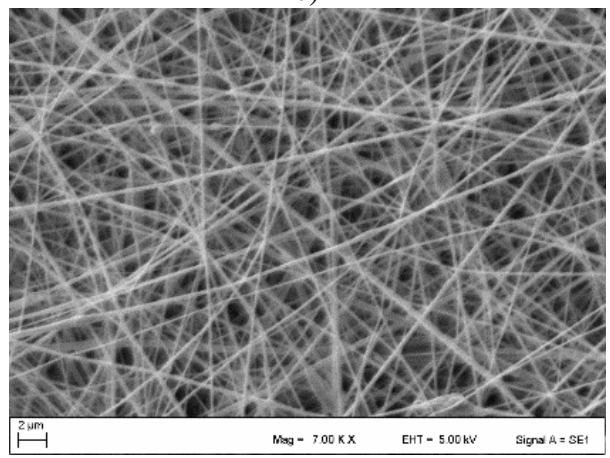

e)

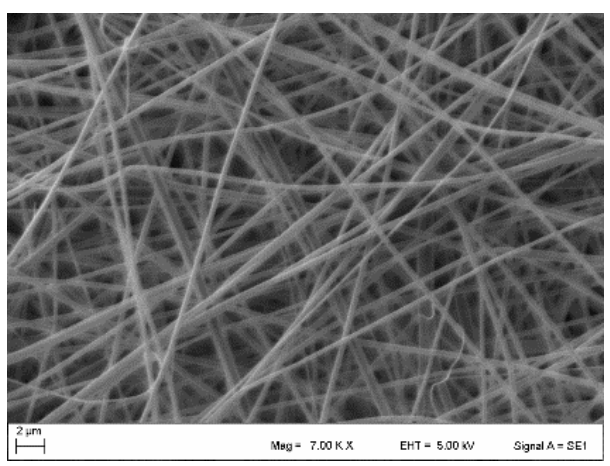

b)

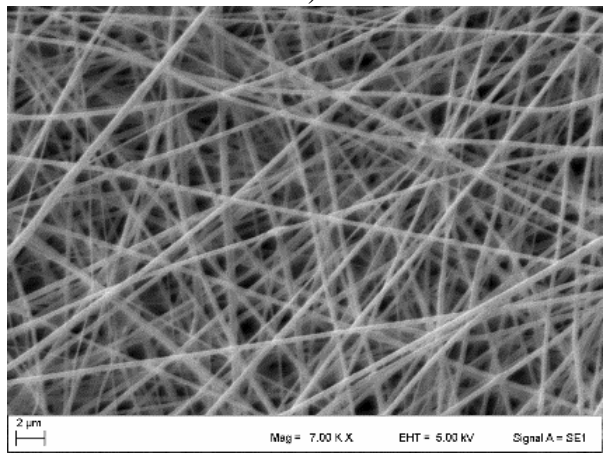

d)

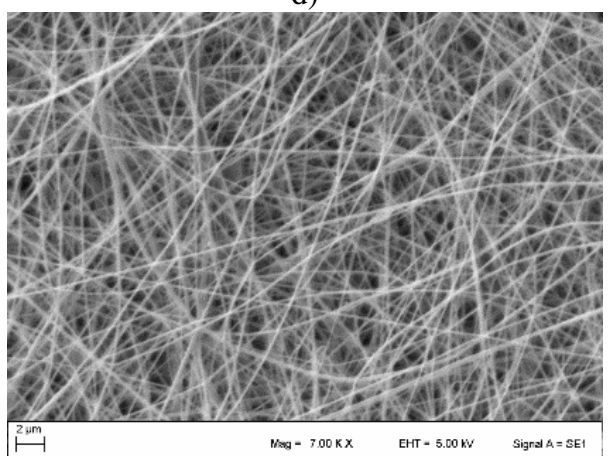

f)

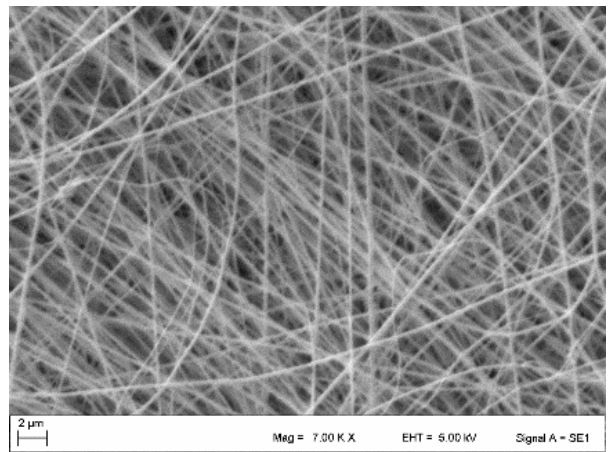

g)

Figure 1: SEM images of produced nanofiber surfaces containing different ratios of LHS/PVP/RGO (7.0 kX); a) LP1, b) LP2, c) LP3, d) LPR1, e) LPR2, f) LPR3, g) LPR4

Twenty different nanofiber diameters were measured from each of the SEM images given in Figure 1 and their mean and standard deviations are given in Table 2. It was observed that smooth nanofiber structures were formed in all the samples. It was observed that only the nanofibers obtained in the LP3 sample in Figure 1 (c) adhered to each other at some points and also 
thicker nanofibers were obtained in this sample. This is thought to be caused by the high viscosity of the LP3 sample. This effect of viscosity is also in agreement with other literature reports. ${ }^{45-46}$ Nezzari et $a l .{ }^{45}$ reported that low concentrations generated jets with insufficient viscoelastic forces to fully suppress droplet breakup due to the Rayleigh instability. They also stated that, in contrast, the increased viscosity of the higher concentration solutions created higher viscoelastic forces that resisted the axial stretching during whipping, resulting in larger fiber diameter. They reported that reduced viscosity resulted in directional instability in the electrostatic force of the solution, which is essential to form uniform fibers. To obtain uniform fiber morphologies, the viscosities of the solutions are more important than the concentrations. When the SEM images in Figure 1 are examined, it is seen that thin and smooth nanofibers, with an average diameter of $415 \pm 97 \mathrm{~nm}$, are obtained from LP1 (8\% PVP/6\% LHS), EtOH/DMF solution without RGO and similarly, smooth nanofibers, with an average diameter of $403 \pm 91 \mathrm{~nm}$, were obtained from the $8 \%$ PVP/7.5\% LHS solution. None of them has beads. It has been observed that the diameters of the nanofibers have decreased slightly with the increase in the amount of LHS in the solution.

In Figure 1 (c), smooth fibers with an average diameter of $537 \pm 131$ nanometers were obtained from 7.5\% LHS/10\% PVP solution. It was observed that the increase in PVP in the solution increased approximately 1.5 times the average fiber diameters. This shows that the amount of PVP in the solution significantly affects the fiber diameter. In Figure 1 (d), the average diameter of nanofibers obtained from $7.5 \%$ LHS/10\% $\mathrm{PVP} / 5.6 \%$ RGO solution varies evenly between $339 \pm 98$ nanometers. Beads are partly observed in the produced fibers. Compared to Figure 1 (c), the average fiber diameters were reduced by approximately 2 -fold as a result of the addition of RGO to the solution, resulting in thinner nanofibers. This result shows that the amount of RGO in the solution has a significant effect on the fiber diameter.

In Figure 1 (e), smooth nanofibers with an average diameter of $277 \pm 76$ nanometers were obtained from 6\% LHS/8\% PVP/5.6\% RGO solution. In Figure 1 (f), the average diameters of the nanofibers obtained from $7.5 \%$ LHS/8\% PVP/5.6\% RGO solution vary around $262 \pm 65$ nanometers. Figure 1 (e) shows that a slight increase in LHS in the solution leads to an increase in fiber diameters.

Figure $1(\mathrm{~g})$ shows that the average diameters of the nanofibers obtained from $7.5 \%$ LHS/10\% $\mathrm{PVP} / 4 \%$ RGO solution vary around $257 \pm 50$ nanometers, with a smooth surface and a small number of beads. It can be seen from Figure 1 (ac) that the amount of PVP in the solutions has a significant effect on the nanofiber diameters, while the amount of LHS has a minor effect on the nanofiber diameters. Compared to the literature on fibers obtained from liquefied wood, it may be noted that finer fibers are obtained in this study. When RGO was mixed into the first three electrospinning solutions, the nanofiber diameters showed a reduction by half. Furthermore, beads were partly seen in the nanofibers when RGO was added.

Tian et al. ${ }^{47}$ investigated the morphologies of electrospun fibers obtained from electrospinning solutions consisting of phenol liquefied wood and polyvinyl pyrrolidone (PVP) using SEM. They obtained decent and uniform fibers, with diameters of around $400 \mathrm{~nm}$ and $900 \mathrm{~nm}$, using $6 \% \mathrm{PVP} /$ ethanol and $8 \% \mathrm{PVP} /$ ethanol solutions, respectively. They found that, in the electrospinning process, the concentration of the macromolecular polymer has an important role in nanofiber morphology. They also observed favorable nanofiber morphology, without beads or crossing points, when liquefied wood and the PVP ethanol solution were mixed in a ratio of 1:1 by weight. Moreover, the diameters of the liquefied wood-based fibers increased significantly and were found as approximately 2.0-4.0 $\mu \mathrm{m}$, compared with those of pure $\mathrm{PVP} / \mathrm{ethanol}$ fibers. This situation was associated with the molecular structure alteration in the solution. They reported that the type of polymer used plays a crucial role in the fiber diameters and fine liquefied wood-based nanofibers could be obtained by using 6\% PVP in the electrospinning solution.

The zeta potential measurements of the solution and the obtained nanofiber surfaces were performed with a Malvern Instruments Zetasizer Nano ZS90. Water was used as solvent. Zeta potential is the measurement of the push or pull value between the particles. The behavior of the beads in polar fluids is determined by the zeta potential values, not the electrical charge on their surface. Zeta potential is affected by $\mathrm{pH}$, molarity and solvent type of a colloidal solution. 
The zeta potential and conductivity values of the nanofiber surfaces obtained from the samples with graphene and LHS solutions are given in Table 3.

When the LP1 and LP2 samples are examined in Table 3, it is seen that the zeta potential of the nanofiber is reduced by approximately $38 \%$ with the addition of LHS to the solution. As the amount of LHS increases, it keeps decreasing. The conductivity of the samples is generally

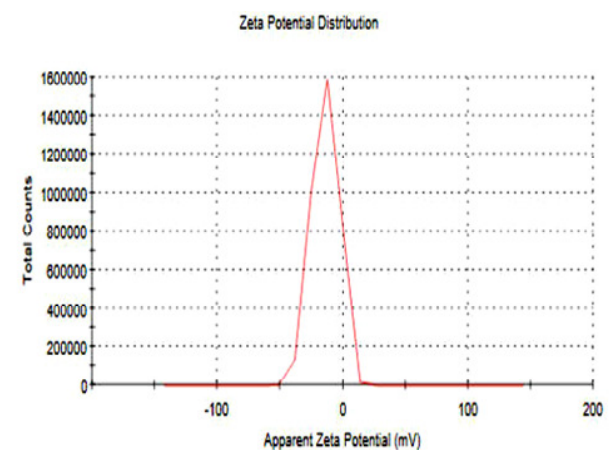

a)

Zeta Potertal Distribution

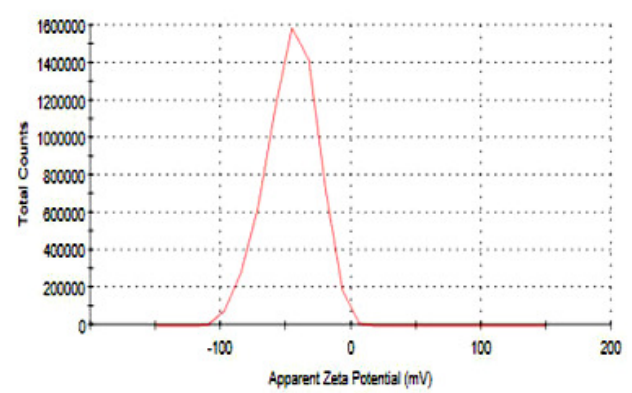

c)

Zeta Potential Distribution

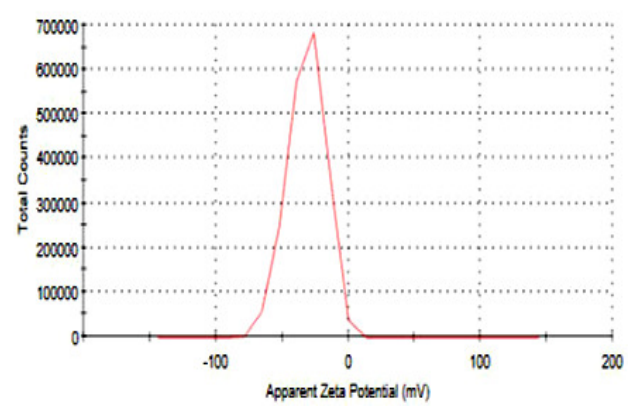

e) decreased in proportion to the decrease in the zeta potential. When comparing samples LP2 and LP3, the increase in the PVP amount increased the nanofiber zeta potential approximately five-fold. The addition of RGO to the LHS/PVP mixture seems to reduce the zeta potential and conductivity of the nanofiber. The zeta potential graphs of nanofibers, RGO and LHS are shown in Figure 2.

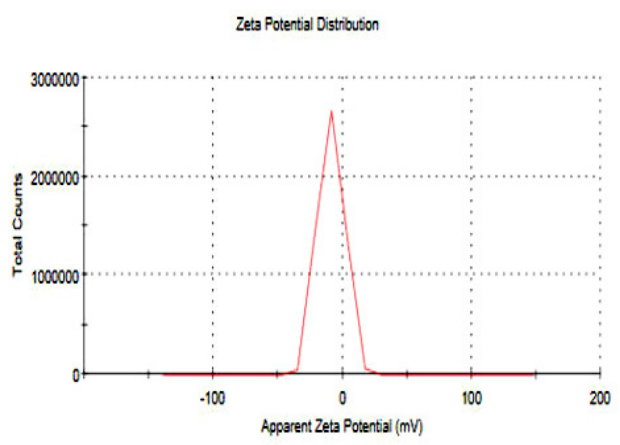

b)

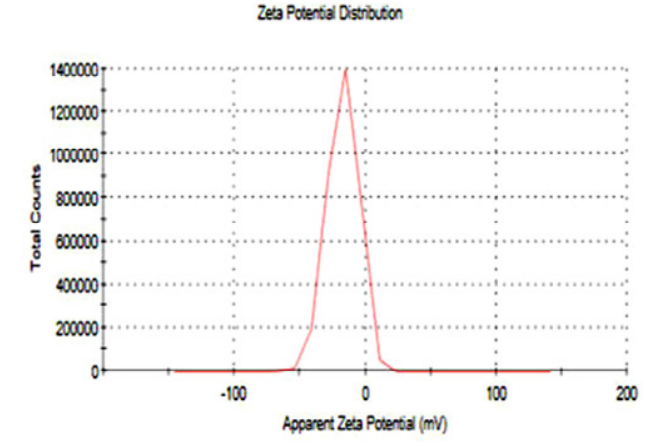

d)

Zeta Potential Distribution

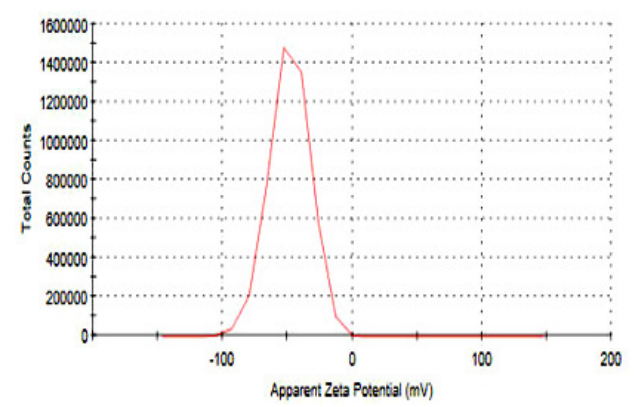

f) 
Nanofibers

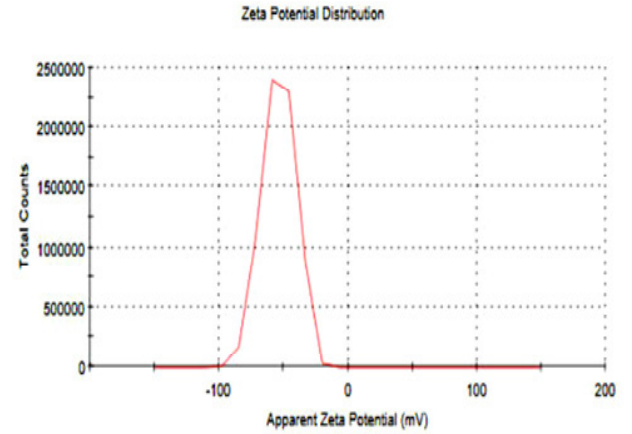

g)

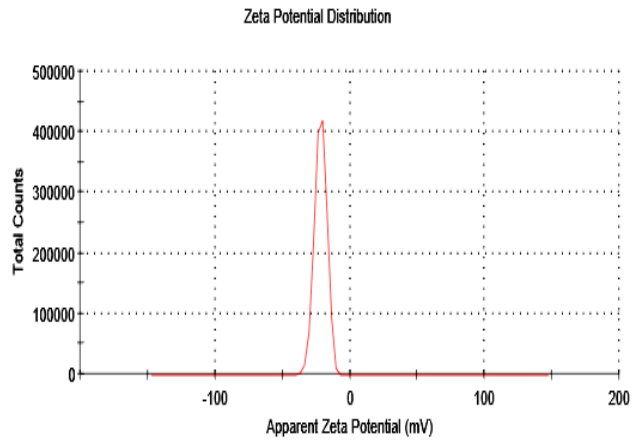

h)

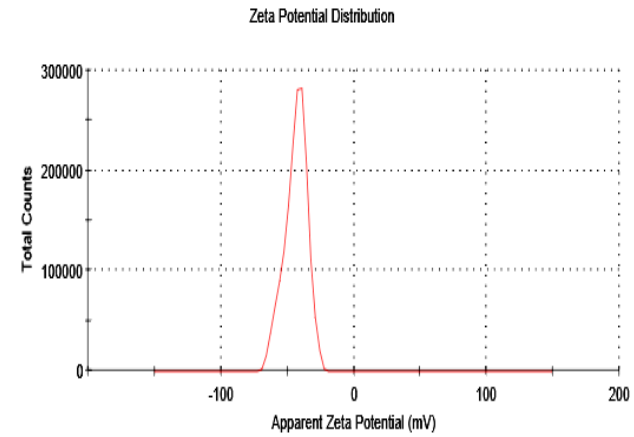

i)

Figure 2: Zeta potential graphs of RGO, LHS and nanofibers; a) LP1, b) LP2, c) LP3, d) LPR1, e) LPR2, f) LPR3, g) LPR4, h) RGO, i) LHS

Table 3

Zeta potential and conductivity values

\begin{tabular}{ccc}
\hline $\begin{array}{c}\text { Sample } \\
\text { code }\end{array}$ & $\begin{array}{c}\text { Zeta potential } \\
(\mathrm{mV})\end{array}$ & $\begin{array}{c}\text { Conductivity } \\
(\mathrm{mS} / \mathrm{cm})\end{array}$ \\
\hline RGO & -21.6 & 0.0465 \\
LP1 & -13.9 & 0.0455 \\
LP2 & -8.69 & 0.0573 \\
LP3 & -45.2 & 0.0367 \\
LPR1 & -17.2 & 0.0123 \\
LPR2 & -29.6 & 0.0218 \\
LPR3 & -48.2 & 0.0357 \\
LPR4 & -53.7 & 0.0679 \\
\hline
\end{tabular}

Balgis et al. produced dual-size nanofibers using a precursor solution containing TEMPOoxidized cellulose nanofibers and polyvinyl pyrrolidone as a polymer source and ethanol-water as a solvent via one-step electrospinning. They reported that the formation of nanofiber composites might be affected by the relationship between the high zeta potential of the cellulose nanofibers and the voltage applied during the electrospinning process. They recorded a $-90 \mathrm{mV}$ negative charge, which is mostly generated by the zeta potential of cellulose. Their results showed that even though the polymer jet generally had a Coulomb explosion, excessive splitting did not occur. The Taylor cone is more stable than that of the reverse charge conditions. Moreover, it was determined that there was no zeta potential effect on polymer jet splitting, which was concluded due to single-size nanofibers (approx. $100 \mathrm{~nm}$ ) produced using several magnitudes of negative voltage. ${ }^{48}$

Malik et al. examined the zeta potential of polyacrylonitrile (PAN)-magnetite $\left(\mathrm{Fe}_{3} \mathrm{O}_{4}\right)$ electrospun composite nanofiber. They found that the zeta potential of the obtained nanofiber was $\mathrm{pH}$ dependent. Different zeta potentials of -18.8 $\mathrm{mV}$ to $-62.3 \mathrm{mV}$ were recorded at $\mathrm{pH} 2.6$ and $\mathrm{pH}$ 7.2 , respectively. It was reported that the $\mathrm{pH}$ 
dependence of the samples indicated that the $\mathrm{Fe}_{3} \mathrm{O}_{4}$ has a shear effect on the surface charge due to the negative surface charge $\mathrm{pH}$ independent PAN nanofiber. They also found that the zeta potential did not change too much at $\mathrm{pH} 6$ and above. $^{49}$

The graphs obtained from the FT-IR analysis of the produced nanofibers are given in Figure 3. It is observed that there are shifts in the wavenumbers and changes in intensity of some peaks of LHS, PVP and RGO in nanofibers, which are close to each other and/or overlap groups. When the peaks detected in the graphs are examined, the wide band seen around $3200 \mathrm{~cm}^{-1}$ belongs to the $\mathrm{OH}$ tension. Since the combination of aliphatic and aromatic $\mathrm{OH}$ groups in cellulose, hemicellulose and lignin structure, especially in LHS content, and the peaks cover each other, the peaks of the $\mathrm{OH}$ groups are enlarged and seen as a band. The peak around $2946 \mathrm{~cm}^{-1}$ shows tensions of $\mathrm{CH}_{3}$ and $\mathrm{CH}_{2}$. The peaks around $1660 \mathrm{~cm}^{-1}$ belong to $\mathrm{C}=\mathrm{O}$ groups. The peaks around 1620 and $1590 \mathrm{~cm}^{-1}$ and the tripartite peaks between 1460 and $1420 \mathrm{~cm}^{-1}$ show $\mathrm{C}=\mathrm{C}$ vibrations of benzene. The peak around $1375 \mathrm{~cm}^{-1}$ shows characteristic C-H bending of cellulosic and hemicellulosic alkanes; the peak around 1290, $1270 \mathrm{~cm}^{-1}$ shows in-plane bending of the $\mathrm{C}-\mathrm{H}$; the peaks around $1227 \mathrm{~cm}^{-1}$ indicate aliphatic $\mathrm{C}-\mathrm{H}$ tension and the peaks around $800 \mathrm{~cm}^{-1}$ indicate off-plane C-H tensions. The peaks around 1030 $\mathrm{cm}^{-1}$ indicate alcohol, carboxylic acid and ester C$\mathrm{O}$ tensions, while the peaks around $570 \mathrm{~cm}^{-1}$ indicate $\mathrm{N}-\mathrm{C}=\mathrm{O}$ bending. As a result, due to the differences in the content of LHS, RGO and PVP in the content of nanofibered surfaces, small differences were found among the FTIR graphs, however, the peaks in these graphs were consistent with those reported in the literature. $^{23,29,50-53}$

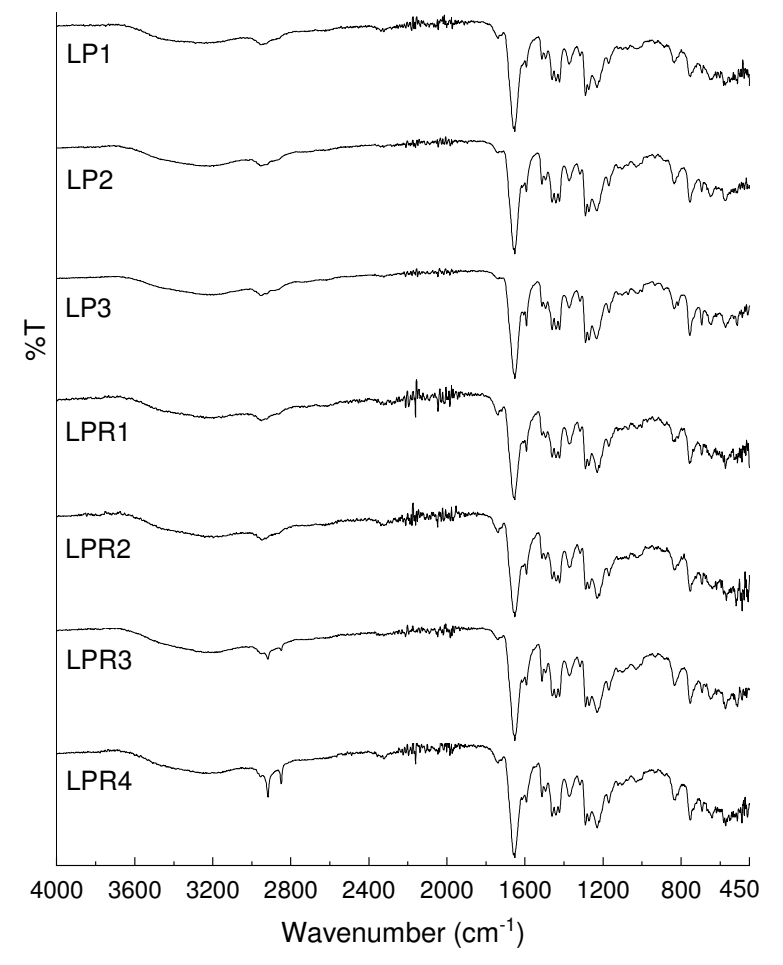

Figure 3: FTIR spectrograms of produced nanofibers

Elayappan et al. prepared porous $\mathrm{TiO}_{2}$ nanofibers by using polyvinyl pyrrolidone (PVP) as a template via the electrospinning technique. They studied the influence of various concentrations of PVP (5, 8 and $10 \mathrm{wt} \%)$ on the chemical properties by using FTIR. They found the absorption bands in the range of 1000-1800 $\mathrm{cm}^{-1}$ correspond to the bending and stretching frequencies of PVP. The characteristic peaks of PVP are identified at $1665 \mathrm{~cm}^{-1}$ and $1288 \mathrm{~cm}^{-1}$ for $\mathrm{C}=\mathrm{O}$ stretching and $\mathrm{C}-\mathrm{N}$ stretching, respectively. The broad peak at $3405 \mathrm{~cm}^{-1}$ in the spectrum was attributed to the $\mathrm{O}-\mathrm{H}$ stretching of physically adsorbed water in the structure. ${ }^{54}$ 


\section{CONCLUSION}

In the electrospinning process, the concentration of the fiber spinning solution plays a very important role in the morphology of the nanofibers produced. In fact, the greater the concentration is, the greater the nanofiber diameter is. SEM analysis was performed to investigate the effect of LHS, PVP and RGO on the diameter of the nanofibers produced by electrospinning. It was observed from the data obtained from SEM analyses that the increase in the LHS ratio slightly increased the nanofiber diameter and also the fiber diameter increased with the increase in the ratio of PVP in the solution. With the addition of RGO into the solution, it was determined that the nanofiber diameter was significantly reduced. This effect of RGO will impart more robustness and higher strength to the produced nanofiber. It is seen from the data that the ideal electrospun nanofiber surfaces were obtained from LPR1 $(7.5 \%$ LHS/10\% PVP/5.6\% RGO) solution by the electrospinning method. It was found that the conductivity decreases slightly, and the viscosity decreases significantly with the addition of RGO to the solution. It was also observed that there was a significant reduction in the diameter of the nanofibers obtained from these solutions and thus thinner nanofibers were obtained.

As hazelnut shell is abundant in Turkey and in the world, this agricultural residue can be turned into one of the most important types of biomass for the production of nanofiber and for liquefaction. The findings of the present study show that LHS can be used as a renewable resource in the production of nanofiber materials and can be a pioneer in the development of new environmentally friendly nanomaterials.

ACKNOWLEDGMENTS: The authors would like to express their gratitude to Kahramanmaraş SütçüImam University, BAP (Scientific Research Projects) unit for its funding support with grant number 2017/1-77 D. The authors declare no potential conflict of interest with respect to the research, authorship, and/or publication of this article.

\section{REFERENCES}

1 Y. P. Wei, F. Cheng, H. P. Li and J. G. Yu, J. Appl. Polym. Sci., 92, $351 \quad$ (2004), https://doi.org/10.1002/app.20023
2 H. Kishi, A. Fujita, H. Miyazaki, S. Matsuda and A. Murakami, J. Appl. Polym. Sci., 102, 2285 (2006), https://doi.org/10.1002/app.24433

3 E. Jasiukaityte, M. Kunaver and M. Strlic, Cellulose, 16, $393 \quad$ (2009), https://doi.org/10.1007/s10570-009-9288-y

4 L. Lin, M. Yoshioka, Y. Yao and N. Shiraishi, J. Appl. Polym. Sci., 52, $1629 \quad$ (1994), https://doi.org/10.1002/app.1994.070521111

5 L. Lin, M. Yoshioka, Y. Yao and N. Shiraishi, $J$. Appl. Polym. Sci., 58, $1297 \quad$ (1995), https://doi.org/10.1002/app.1995.070580811

6 M. H. Alma, D. Maldas and N. Shiraishi, J. Polym. Eng., 18, 161 (1998), https://doi.org/10.1515/POLYENG.1998.18.3.I

7 M. Kobayashi, T. Asano, M. Kajiyama and B. J. Tomita, Wood Sci., 50, 407 (2004), https://doi.org/10.1007/s10086-003-0596-9

8 M. H. Alma, M. Yoshioka, Y. Yao and N. Shiraishi, Wood Sci. Technol,, 30, 39 (1995), https://doi.org/10.1007\%252FBF00195267

9 M. H. Alma and N. Shiraishi, J. Polym. Eng., 18, 179

https://doi.org/10.1515/POLYENG.1998.18.3.179

(1998),

10 M. H. Alma, M. Yoshioka, Y. Yao and N. Shiraishi, Holzforschung, 50, 85 (1996), https://doi.org/10.1515/hfsg.1996.50.1.85

11 L. Lin, Ph.D. Thesis, Kyoto University, Kyoto, Japan, 1996

12 T. C. Gümrükve Ticaret Bakanlığı Kooperatifçilik Genel Müdürlüğü (TR Ministry of Customs and Trade), "2017 Yilı Findık Raporu”, Ankara, 2018, https://ticaret.gov.tr/data/5d41e59913b87639ac9e02e8/ 5c41e34d540794faaa011bdfa3466ff3.pdf

13 I. Ghosh, Q. Haider and C. Sharma, Cellulose Chem. Technol., 53, 643 (2019), https://doi.org/10.35812/CelluloseChemTechnol.2019. 53.63

${ }_{14}$ H. Qi, C. Chang and L. Zhang, Green Chem., 11, 177 (2009), https://doi.org/10.1039/B814721C

15 X. You, K. Koda, T. Yamada and Y. Uraki, Holzforschung, $\quad 69, \quad 1097 \quad$ (2015), https://doi.org/10.1515/hf-2014-0262

16 T. H. Radoykova, T. G. Angelova, P. S. Vassileva, N. V. Georgieva, A. K. Detcheva et al., Cellulose Chem. Technol., 53, 427 (2019), https://doi.org/10.35812/CelluloseChemTechnol.2019. 53.43

17 F. Akman, Cellulose Chem. Technol., 53, 243 (2019),

https://doi.org/10.35812/CelluloseChemTechnol.2019. 53.24

18 K. S. D. Nunes and L. C. Pardini, Cellulose Chem. Technol., $\quad 53, \quad 227 \quad$ (2019), https://doi.org/10.35812/CelluloseChemTechnol.2019. 53.23

19 X. Ma and G. Zhao, Fib. Polym., 9, 405 (2008), https://doi.org/10.1007/s12221-008-0065-6 
20 R. Li, S. Wang, A. Lu and L. Zhang, Cellulose, 22, 339 (2015), https://doi.org/10.1007/s10570-014-05426

21 D. Allouch, M. Popa, V. I. Popa, G. Lisa, A. C. Puițel et al., Cellulose Chem. Technol., 53, 851 (2019), https://doi.org/10.35812/CelluloseChemTechnol.2019. 53.82

22 J. Hoffman, T. H. Pedersen and L. A. Rosendahl, in "Near-Critical and Supercritical Water and Their Applications for Biorefineries, Vol. 2: Biofuels and Biorefineries", edited by Z. Fang, C. C. Xu, Springer Science + Business Media Dordrecht, 2014, pp. 373400

23 G. Gözaydın, M.Sc. Thesis, İzmir Yüksek Teknoloji Enstitüsü, Mühendislikve Fen Bilimleri Enstitüsü, İzmir, Turkey, 2016, https://tez.yok.gov.tr/UlusalTezMerkezi/TezGoster?ke $\mathrm{y}=710 J X 8 \mathrm{w} \_8$ PRQU1mSHU6joQPYMXII3116al1k2szmSwQ48UT0HKDZIic7fRAh oub

24 Y. Huang, L. Peng, Y. Liu, G. Zhao, J. Y. Chen et al., ACS Appl. Mater. Interfaces, 8, 15205 (2016), https://doi.org/10.1021/acsami.6b02214

${ }^{25}$ Z. Tian, W. Zhang and W. Lu, Nanomater. Nanotechnol., $\quad 6, \quad 6 \quad 1$ (2016) https://doi.org/10.5772/62287

26 Q. Yang, Z. Li, Y. Hong, Y. Zhao, S. Qiu et al., J. Polym. Sci. Part B: Polym. Phys., 42, 3721 (2004), https://doi.org/10.1002/polb.20222

27 M. Yazıc1, İ. Tiyek and M. H. Alma, "Elektromanyetik Kalkanlama Amaçlı Grafen Katkılı Spunbond ve Meltblown Tekstil Yüzeylerinin Üretilmesi ve Grafenin Kalkanlanma Verimine Etkisinin Araştırılması" [Production of Graphene Doped Spunbond and Meltblown Textile Surfaces for Electromagnetic Shielding Purposes and Investigation of the Effect of Graphene on Shielding Efficiency], 2017, Tübitak Proje No: 114M527

28 A. A. Topçu, M.Sc. Thesis, Koç University, Material Science and Engineering, İstanbul, Turkey, 2012

https://tez.yok.gov.tr/UlusalTezMerkezi/TezGoster?ke y=RYan9_S-Z7Eir3xdWGXBiJdIX3rj6EeTxHBFvkRzJnHyOrfI6AtEjBJoNPhfsUZ

29 İ. Tiyek, U. Dönmez, B. Yıldırım, M. H. Alma, M. S. Ersoy et al., Sakarya Üniversitesi Fen Bil. Enst. Dergisi, $\quad 20, \quad 349 \quad$ (2016), https://doi.org/10.16984/saufenbilder.29009

30 R. Majidi and H. R. Taghiyari, Cellulose Chem. Technol., $\quad 53, \quad 411 \quad$ (2019), https://doi.org/10.35812/CelluloseChemTechnol.2019. 53.41

31 Z. Çıplak, M.Sc. Thesis, Ankara Üniversitesi, Fen Bilimleri Enstitüsü, Ankara, Turkey, 2013, https://tez.yok.gov.tr/UlusalTezMerkezi/TezGoster?ke $\mathrm{y}=\mathrm{vVNzTGHHhjH-u3WMToxQ}$ -

mKuS51luwzX1S9su87cmDaRLpaAH7ncqQVan5pBy bia
32 M. Yazıc1, İ. Tiyek, M. S. Ersoy, M. H. Alma, Ş. Karataş et al., Gazi Üniversitesi J. Sci. Part C, 4, 41 (2016), https://dergipark.org.tr/en/download/articlefile/229775

33 M. H. Alma, M. Yazıcı, B. Yıldırım, T. Salan and İ. Tiyek, Tekstilve Mühendis Dergisi, 24, 243 (2017), https://doi.org/10.7216/1300759920172410803

34 S. Park and R. Ruoff, Nature Nanotechnol., 4, 217 (2009), https://doi.org/10.1038/nnano.2009.58

35 H. Kim, A. A. Abdala and C. W. Macosko, Macromolecules, 43, $6515 \quad$ (2010), https://doi.org/10.1021/ma100572e

36 C. Menchaca-Campos, C. García-Pérez, I. Castañeda, M. A. García-Sánchez, R. Guardián et al., Int. J. Polym. Sci., 2013, 1 (2013), https://doi.org/10.1155/2013/621618

37 İ. Tiyek, M. Yazıcı, M. H. Alma and Ş. Karataş, $J$. Comp. $\quad$ Mater., 53, $1541 \quad$ (2019), https://doi.org/10.1177/0021998318806973

38 S. Pei and H. M. Cheng, Carbon, 50, 3210 (2012), https://doi.org/10.1016/j.carbon.2011.11.010

39 Kenry and C. T. Lim, Prog. Polym. Sci., 70, 1 (2017),

https://doi.org/10.1016/j.progpolymsci.2017.03.002

${ }^{40}$ L. Tao, Y. Zheng, Y. Zhang, M. Di and Z. Zheng, J. Porous Mater., 25, $521 \quad$ (2018), https://doi.org/10.1007/s10934-017-0464-4

${ }^{41}$ C. Wang, Y. Li, G. Ding, X. Xie and M. Jiang, $J$. Appl. Polym. Sci., 127, $3026 \quad$ (2013), https://doi.org/10.1002/app.37656

42 S. H. Ryu and A. M. Shanmugharaj, Chem. Eng. J., 244, 552

(2014), https://doi.org/10.1016/j.cej.2014.01.101

43 J. Chen, B. Yao, C. Li and G. Shi, Carbon, 64, 225 (2013), https://doi.org/10.1016/j.carbon.2013.07.055

44 C. J. Angammana and S. H. Jayaram, IEEE Trans. Ind. Appl., 47, $1109 \quad$ (2011), https://doi.org/10.1109/TIA.2011.2127431

${ }_{45}$ R. M. Nezarati, M. B. Eifert and E. CosgriffHernandez, Tissue Eng. Part C: Methods, 19, 810 (2013), https://doi.org/10.1089/ten.tec.2012.0671

46 J. Tao and S. Shivkumar, Mater. Lett., 61, 2325 (2007), https://doi.org/10.1016/j.matlet.2006.09.004

47 Z. Tian, W. Zhang and W. Lu, Nanomater. Nanotechnol., $\quad \mathbf{6 ,} \quad 1$ (2016), https://doi.org/10.5772/62287

48 R. Balgis, H. Murata, Y. Goi, T. Ogi, K. Okuyama et al., Langmuir, 33, $6127 \quad$ (2017), https://doi.org/10.1021/acs.langmuir.7b01193

${ }^{49}$ H. Malik, U. A. Qureshi, M. Muqeet, R. B. Mahar, F. Ahmed et al., Environ. Sci. Pollut. Res., 25, 3557 (2018), https://doi.org/10.1007/s11356-017-0706-7

50 Y. J. Song, M. Wang, X. Y. Zhang, J. Y. Wu and T. Zhang, Nanoscale Res. Lett., 9, 1 (2014), https://doi.org/10.1186/1556-276X-9-17

51 K. M. Koczkur, S. Mourdikoudis, L. Polavarapu and S. E. Skarabalak, Dalton Trans., 44, 17883 (2015), https://doi.org/10.1039/C5DT02964C 
52 K. Kamaruddin, D. Edikresnha, I. Sriyanti, M. M. Munir and K. Khairurijal, in Procs. The $4^{\text {th }}$ Internatinal Conference on Advanced Material Science and Technology, Indonesia, September 27-28, 2017, pp. 17, https://doi.org/10.1088/1757-899X/202/1/012043

53 E. Demirkaya, O. Dal and A. Yüksel, J. Supercrit. Fluids, 150,

11

(2019),

https://doi.org/10.1016/j.supflu.2019.03.019

54 V. Elayappan, P. Panneerselvam, S. Nemala, K. S. Nallathambi and S. Angaiah, Appl. Phys. A, 120, 1211 (2015), https://doi.org/10.1007/s00339-015-9306-X 